British Journal of Psychiatry (1991), 159, 582-596

\title{
Correspondence
}

Editor: Ian Pullen

Contents: Withdrawal from heroin and methadone/ Cerebral ventricular size and dyskinesia/Verapamil in major depression?/Psychogenic amnesia?/Clinical interviews with children and adolescents/Portrayal of women in advertisements/Independent evaluation of new drugs/Winnicott's contribution/Incidence rates of schizophrenia/Ethnic nomenclature/Medical Research Council/Pathological jealousy defined/ Access to health records/Anorexia nervosa in Asian children/The clinical application of restricted environmental stimulation therapy (REST): observations of a psychiatrist/Is oncogene activity involved in the alcohol withdrawal syndrome?/Politically motivated suicides/NMS and genetic drug oxidation.

\section{Withdrawal from heroin and methadone}

SIR: Psychological and social factors are very important in the institution and maintenance of addictive behaviour. Complex issues arise when methadone is used in conjunction with prescribed or abused drugs (Zweben \& Payte, 1990). Gossop \& Strang (Journal, May 1991, 158, 697-699) caution us that methadone addicts report more severe withdrawal responses than heroin addicts during an in-patient gradual methadone reduction programme. However, we are not provided with any patient profiles, or details of length of drug abuse and other drugs abused, and no indication of the mental state of the patients included is offered. Hence, no acknowledgement of motivational factors or coping strategies employed in withdrawal is allowed (Murphy et al, 1989). Furthermore, it would appear that the ten-day methadone reduction schedule was chosen arbitrarily, even though the authors themselves recently highlighted the benefits and handicaps of various withdrawal schedules (Gossop et al, 1989). Withdrawal responses were only measured with the self-rating short opiate withdrawal scale (SOWS). However, a lack of correlation has been found between patients' subjective ratings, objective nurse ratings and physiological parameters of withdrawal severity (Turkington \& Drummond, 1989). It is very important in this type of research that subjective and objective dimensions of withdrawal be considered and measured separately.
The authors state that there was no difference between the heroin and methadone subjects in terms of either detoxification completion rates or total length of stay on the unit. This prompts me to question the relevance of the differences noted on the SOWS, since the outcomes in both groups were comparable. We are told of special difficulties that may arise during the withdrawal phase as a result of the prior substitution of methadone for heroin. I wonder what is meant by this? The literature suggests that use predicts treatment outcome, not opiate dependence or withdrawal (Kosten et al, 1989).

Notwithstanding the above criticisms, the results showing differences between the two groups are intriguing. Most theories of drug tolerance emphasise the physiological consequences of repeated pharmacological stimulation; they postulate some systemic change within the organism, as a result of early administrations, that either modifies receptor sensitivity to the drug, induces neurochemical changes, or alters the metabolism of the drug. However, a complete account of tolerance requires an appreciation of environmental influences. In this study, the group with the most severe withdrawal was the group that was already established on methadone. The heroin group differed in that they had to accept that before entry, a condition of treatment would be substituting their heroin for methadone. The latter group were aware that their drug cues would be different, the former experienced their old cues (i.e. methadone) but in a different context. Could it be that the differences in severity of withdrawals observed reflect an appreciation of environmental alterations?

Gossop, M., Griffiths, P., Bradley, B. el al (1989) Opiate withdrawal symptoms in response to 10-day and 21-day methadone withdrawal programmes. British Journal of Psychiatry. 154, 360-363.

Kosten, T. A., Bianchi, M. S. \& Kosten, T. R. (1989) Use predicts treatment outcome, not opiate dependence or withdrawal. NIDA Research Monograph, 95, 459-460.

Murphy, P. N., Bentall, R. P. \& OWEns, R. G. (1989) The experience of opioid abstinence: the relevance of motivation and history. British Journal of Addiction, 84, 673-679.

Turkington, D. \& Drummond, D. C. (1989) How should opiate withdrawal be measured? Drug and Alcohol Dependence. 24, 151-153. 
ZWEBEN, J. E. \& PAYTE, J. T. (1990) Methadone maintenance in the treatment of opioid dependence. A current perspective. Western Journal of Medicine, 152, 588-599.

\section{RAYMOND TRAVERS}

Olive Mount Hospital

Old Mill Lane

Wavertree

Liverpool L15 8LW

AUTHORS' REPLY: Dr Travers raises questions but offers few solutions. He is of course correct that there are many influences on the opiate withdrawal syndrome in addition to that described in our paper (Journal, May 1991, 158, 697-699). However, while clinical practice might necessarily involve juggling with all of these simultaneously, the systematic study of these possible modifying factors requires a different strategy. We have previously reported on the differences between 10-day and 21-day withdrawal regimens (Gossop et al, 1989) and on the influences of different reduction curves (Strang \& Gossop, 1988). Dr Travers rightly draws attention to the difficulty in identifying the relevant measures for the study of the opiate withdrawal syndrome. We are of the view that the SOWS (for development and validation see Gossop, 1990) and the actual measure of completion rates provide two differing and valuable perspectives. When all the criticism is said and done, what does Dr Travers actually suggest?

The most interesting points of the criticism are in the last paragraph where consideration is given to the possible different influence of methadone on heroin or methadone addicts. As we explained in the paper, virtually all of our subjects had originally been using heroin, and were assigned to the two groups according to their most recent opiate of use before admission. Thus if drug cues are being considered, it is unlikely that they would be substantially different across the two groups. Perhaps it is being suggested that the drug cues may relate to the preparation being used - the linctus - but this is unlikely as we use a differently coloured and specially prepared linctus on our inpatient programme. There are also important cognitive cues that influence withdrawal responses. Some of these have been considered by Wikler (1980) as well as in our own previous research.

Finally, Dr Travers questions whether the findings are of any relevance in view of the similar discharge rates. From a clinical management perspective there may be some legitimacy to this point of view, although we would have thought that reducing the levels of within-treatment distress remained a legitimate clinical goal, notwithstanding the similar completion rates. However, we would also draw attention to a more general point: for too long the treatment of addicts has muddled along, driven by chemical whim, with insufficient investment in the systematic study of the treatment being delivered.

\author{
Gossop, M. (1990) The development of a short opiate withdrawal \\ scale (SOWS). Addictive Behaviors, 15, 487-490. \\ -, Griffiths, P., BrADleY, B. et al (1989) Opiate withdrawal \\ symptoms in response to 10-day and 21-day methadone with- \\ drawal programmes. British Journal of Psychiatry, 154, 360-363. \\ GREEN, L. \& Gossop, M. (1988) The effects of information on the \\ opiate withdrawal syndrome. British Journal of Addiction, 88, \\ 305-309. \\ StRANG, J. \& Gossop, M. (1990) Comparison of linear versus inverse \\ exponential methadone reduction curves in the detoxification of \\ opiate addicts. Addictive Behaviors, 15, 541-547. \\ WIKLER, A. (1980) Opiate Dependence: Mechanisms and Treatment. \\ London and New York: Plenum Press. \\ John STRang \\ Drug Dependence Clinical Research and \\ MichaEl GosSOP \\ Treatment Unit \\ The Bethlem Royal Hospital \\ Monks Orchard Road \\ Beckenham \\ Kent BR3 3BX
}

\section{Cerebral ventricular size and dyskinesia}

SIR: McClelland and colleagues (Journal, May 1991, 158, 691-696) report an interesting association between cerebral ventricular size, at the end of 16years follow-up and the development of facial dyskinesia during the period in a group of 23 patients with functional psychosis. This data adds to 12 previous studies, the results of which divide evenly between supporting and refuting an association between current ventricle:brain ratio (VBR) and current dyskinesia. A smaller group of studies are divided over the importance of cortical atrophy. A confounding problem in McClelland $e t$ al's findings may be the effect of ageing on brain structure. While the 18 years from first assessment for dyskinesia to computerised tomography (CT) scan would be accompanied by some ventricular changes, it would also be accompanied by some development of cortical atrophy. This is particularly likely in those patients who converted from dyskinesia negative to positive as their mean age at first assessment was 53 years. Thus it may be equally possible that the development of dyskinesia in this group could be associated with cortical atrophy.

Recent findings of our own would support this view (Cooper et al, 1991). We have found no relationship between VBR and the presence or absence of 